\title{
HIV-Infections in Male Youths: Risks Associated with Alcohol Misuse
}

\author{
Eugene Gabriel Machimana \\ University of Pretoria, SOUTH AFRICA \\ Department for Education Innovation, Unit for Community Engagement
}

Phillip Nhlanhla

University of South Africa, SOUTH AFRICA

Department of Sociology, College of Human Sciences

Petronella Nondumiso Nompilo Machimana

Military Psychological Institute, Pretoria, SOUTH AFRICA

Martin Chukwudi Ekeh

University of Pretoria, SOUTH AFRICA

Department of Early Childhood

Received: 18 February 2021 - Accepted: 5 April 2021 • Published Online: 6 May 2021

\section{Abstract}

The purpose of the study was to explore the influence of alcohol misuse in HIV-infection at the Health and Welfare Organisation in South Africa. . There is an association between alcohol misuse and HIV transmission. Male youths may lack understanding of the effects of alcohol on their sexual behavior when under the influence of alcohol. This makes male youths vulnerable to HIV infection. Qualitative methodology was used for an in-depth understanding of the phenomenon under investigation. The findings indicate that many male youths are aware of HIV-preventative methods, but their behavior is not always in line with what they know. Therefore, we recommend that male youths should be taught about the risk of HIV infection associated with alcohol misuse in various places such as schools and taverns. HIV/AIDS education should emphasize practical intervention strategies. Condom use should not be neglected in favor of newer preventative strategies such as male circumcision and pre-exposure prophylaxis.

Keywords: alcohol misuse, HIV/AIDS, HIV-prevention, male youths, sexual transmitted infections, risky behavior.

(C) Authors. Terms and conditions of Creative Commons Attribution 4.0 International (CC BY 4.0) apply. Correspondence: Eugene Gabriel Machimana, University of Pretoria, Department for Education Innovation, Unit for Community Engagement, Hatfield, Pretoria, SOUTH AFRICA. Email: 


\section{Introduction}

The problem of excessive consumption of alcohol (misuse) is increasing, yet it is associated with high sexual risks behavior that could transmit HIV. The purpose of the current study sought to explore the risk of alcohol misuse and its association with HIV-infection at the Health and Welfare Organisation (HWO) in Soshanguve in the province of Gauteng, South Africa. The HWO engages with youths in their HIV-prevention program, and some of them are living with HIV. Kalichman, Simbayi, Vermaak, Jooste and Cain (2008) note that people who have a pattern of excessive drinking of alcohol tend to engage in unprotected sex for sensation. This includes both anal and vaginal sex, with the former being more dangerous in terms of the likelihood of transmitting HIV. Some people who misuse alcohol have either shared injecting equipment in the past or are likely to have had a sexual partner who was an injecting drug-user (Kalichman et al., 2008; Parry, Rehm, \& Morojele, 2010). This practice further impedes HIV-prevention strategies.

- Alcohol misuse is associated with HIV transmission.

- Many male youths are aware of HIV-preventative methods, but their behavior is not always in line with what they know.

- We recommend that male youths should be taught about the risk of HIV infection associated with alcohol misuse in various places such as schools and taverns.

- HIV/AIDS education should emphasize practical intervention strategies.

- Condom use should not be neglected in favor of newer preventative strategies such as male circumcision and pre-exposure prophylaxis.

The management of the HWO was very interested in the study during and after the negotiations for access to conduct the study. The study has a potential to contribute scientific data and also add to the store of new knowledge, for the institution to use when they develop policies and procedures to address the association between alcohol misuse and the risk of HIV-infection. The fact that the HWO has a hospice amongst its programs alludes to the challenge of HIVinfections in this community. In light of this scenario, the current study could benefit the HWO when they develop HIV-prevention programs and policies that are relevant to youths.

\section{Literature review}

\subsection{Prevention of HIV transmission}

HIV is transmitted from an individual who is living with the virus (HIV positive) to an individual who is not living with the virus (HIV negative) in several ways. Ndinga-Mavumba and Pharoah (2008) note that HIV can be transmitted sexually or through direct contact with infected fluid or blood. An example of this can be transmission through blood transfusions or through the use of contaminated needles. The National Institute on Alcohol Abuse and Alcoholism (2002) attest that alcohol is linked to two main modes of HIV transmission, namely high-risk sexual behaviors and injective drug use. Although there are several ways in which HIV can be transmitted, Piot (2003) argues that HIV is mainly transmitted through unprotected sexual intercourse with an infected person. It is wise for individuals to practice safer sex by using condoms correctly and avoiding contaminated needles to prevent HIV-infection. Because of the argument that HIV is transmitted mainly through sexual intercourse, the focus of the current study was on sexual risky behavior under the influence of alcohol rather than ascertaining other risky behaviors associated with HIV.

Ndinga-Mavumba and Pharoah (2008) state that South Africa has reached the peak of the AIDS pandemic, and sexual behavior change is non-negotiable for moving forward in 
tackling the disease. HIV-prevention programs aimed at empowering youths are critically needed as young adults are disproportionally at higher risk of HIV infection (Maljaars et al., 2017). LoveLife (2020) advocates the holistic engagement of youths in HIV-prevention programs by addressing issues such as leadership, activism, agency, self-awareness, poverty, gender inequality, positive role models and effective communication. LoveLife (2020) is concerned about the negative socialization of boys; hence the organization developed the Boy child project aimed at empowering young boys to deal with life challenges in a better way. Parents cannot neglect their responsibility to facilitate social learning and raise awareness of HIV with their adolescents, otherwise, adolescents will rely on their peers for HIV information, which may be misleading and detrimental to preventative programs (Perrino, Gonzalez-Soldevilla, Pantin \& Szapocznik, 200o). The communication about sexuality between the parents and adolescents should be sufficient to build confidence between the two parties to talk openly about the subject.

Moreover, in understanding youths, it is also vital to recognize that many developmental milestones converge at this stage of their life such as increased cognitive development, psychological, social and structural transitions (Maljaars et al., 2017). Van Dyk, Tlou and Van Dyk (2017) point out that as youths develop; they need support in building their decisionmaking skills, especially given the peer pressure and personal stress they encounter. Welldeveloped youths who are empowered in every aspect of their life, such as economic and gender relations, are most likely to make good decisions about their lives. Empowered youths would play a pivotal role in HIV-prevention as they make good decisions in terms of sexual behavior.

To date, antiretroviral therapy (ART) is mainly used for reducing the HIV viral load in the blood system of a person living with HIV (Van Dyk et al., 2017). If the HIV viral load of a person on ART was prevented from increasing in the blood, this was an indication that the virus was being managed well. ART prevents the rapid development of active HIV, which leads to the AIDS stage. When a patient is at the AIDS stage, they are vulnerable to opportunistic diseases such as Tuberculosis (TB) (Majozi, 2009; Machimana, 2012). ART was used to improve the immune system, thus preventing opportunistic diseases such as TB, which is the leading cause of AIDS related-deaths in South Africa, from progressing rapidly (Karim \& Karim, 2010).

Alcorn (2011) argues that a new study (Treatment as prevention) shows that ART prevents up to $96 \%$ of HIV infections. The drive to turn treatment to prevention brings new hope in the fight against HIV, because ART can now be used for HIV-prevention purposes. The study of treatment as prevention was conducted in Malawi, Zimbabwe, Botswana, Kenya, South Africa, Brazil, Thailand, the United States of America (USA) and India and 1,763 serodiscordant couples participated (Alcorn, 2011). In the African region, women were mostly HIV positive between the serodiscordant couples, meaning either of the partners was HIV positive and the other HIV negative. Treatment could have full impact in preventing HIV if the delivery of health care is improved and the rights of people living with HIV are respected (Alcorn, 2011). Karim and Karim (2010) state that in South Africa, prevention of opportunistic diseases will remain critical in the fight against the spread of HIV. The following sub-topics discuss various HIV-preventative strategies in detail.

\subsubsection{Addressing alcohol misuse as a strategy for HIV-prevention}

Khosa et al. (2018) argue that the high levels of alcohol consumption among male youths in South Africa increase their chances of HIV infection. There is an association between alcohol misuse and HIV transmission. A study conducted amongst school-going adolescents concerning substance abuse indicates that more than a third of male students in Cape Town and over half of male students in Durban report binge drinking and drug abuse, making them vulnerable to risky sexual behavior (Parry, Myers \& Thiede 2003; Parry et al., 2010). The HIV risky behavior gives cause for concern because youths are the country's future workforce. 
Drinking patterns with drug injection and or risky sex behaviors are primary modes of HIV transmission (Kalichman et al., 2008). Male youths who misuse alcohol and subsequently inject drugs are at a higher risk of contracting HIV from contaminated injection equipment because being under the influence of alcohol impairs their knowledge and skills to protect themselves (Woods, 2004; Machimana, Sefotho, Ebersöhn \& Shultz, 2020). An adolescent may lack experience of the effects of alcohol, and their sexual exploration makes them even more vulnerable.

Their peers sometimes influence inexperienced adolescents in risky sexual behavior. Santrock (2018) explains the theory about adolescents being confused about their identity if they do not adequately explore it. In such cases, they may be swallowed up by the crowd, meaning peers, playing a role in influencing risky sexual behaviors (Shisana et al., 2014). The theory of adolescent development was informative to this research, as many of the research participants were at this stage.

According to Evian (2003), Majozi (2009) and Machimana (2012), alcohol abuse encourages youths to have unsafe sex. Alcohol specifically impairs their judgment and, as a result, they are less cautious when under the influence. The study by Parry et al. (2003) also confirms that youths participate in unsafe sex when they are under the influence of alcohol. The concept of masculinity highlighted above is deeply entrenched within our society and as such male youths take on roles that are "culturally acceptable". Many male youths, therefore, engage in risky sexual behaviors not for the behaviors themselves, but to gain approval in society.

The National Institute on Alcohol Abuse and Alcoholism (2002) asserts that HIV patients who are treated for alcohol abuse show signs of a decrease in consumption of other drugs that have an equally negative impact on the immune system. The treatment of alcohol and other drug abuse forms part of the primary HIV-prevention strategy (Velloza et al., 2015). Alcohol misuse increases susceptibility to some sexually transmitted infections (STIs), such as syphilis and gonorrhea, which facilitates HIV infection (Simbayi, Mwaba \& Kalichman, 2006). It is worth noting that alcohol does not directly cause STIs; nevertheless, alcohol misuse increases sexualrisky behavior (Rees, Saitz, Horton \& Samet 2001). The National Institute on Alcohol Abuse and Alcoholism (2002) claims that alcohol abuse is associated with delays in seeking treatment and non-adherence to HIV medication. It is, therefore suggested that treating alcohol abuse would reduce the risk for AIDS patients.

\subsubsection{HIV-prevention and alcohol policy consideration}

According to Fassin and Scheider (2003), South Africa has moved away from the political position Thabo Mbeki had taken when he inferred that HIV was not the sole cause of AIDS. Ledwaba (2010) remarks that the current political leadership accepts that HIV causes AIDS, and it is investing R40 billion annually in the ART program. The government's new stance on the AIDS pandemic is putting South Africa on good terms with the health profession. However, alcohol is putting an economic burden of over R8.7 billion per year on medical resources (Parry et al., 2003). Youths who misuse alcohol contribute to the economic cost of the country. The economic costs are incurred in treatment, trauma, mortality and crime.

Parry et al. (2003) also hold the opinion that a large proportion of South Africans consume alcohol. The problem of excessive alcohol consumption highlights the need to enforce policies concerning alcohol to reduce the cost associated with drinking, for example, the high medical cost of treatment and youths dropping out of school. Parry (2005) suggests that increasing the minimum legal age for purchasing alcohol to 21 years may help reduce some of the risky behaviors among youths. Increasing taxes and restricting hours for selling alcohol may make it difficult for youths to access alcohol, and this could reduce the risk of HIV-infection. These are 
some of the strategies that may affect addressing the challenges of the spread of HIV associated with alcohol misuse.

\subsubsection{The male condom, circumcision and pre-exposure prophylaxis}

AIDS is a preventable disease if people take the correct measures against HIVinfection. It is scientifically established that people who use condoms consistently and correctly have managed to prevent the transmission of HIV. Van Dyk et al. (2017) assert that condoms are the safest method of protection, and they provide a high level of protection against HIV and other STIs if they are used consistently and correctly. Lancet (2007) reports that condoms offer about $80 \%$ to $90 \%$ protection against sexual transmission of HIV. Shisana et al. (2014) report that a large percentage of youths aged 15 to 24 years show a very strong orientation towards condom use and appreciation of its preventative measure. The male partner often initiates condom use, but the preventative benefits are for both partners involved in sexual intercourse (Majozi, 2009). Albertyn (2003: 600) states that male partners decide the conditions and time of sex, "giving women little opportunity to discuss or practice safe sex". Practices such as this perpetuate gender inequality whereby males dominate their female counterparts in sexual relations and how it should be conducted.

It is recommended that condoms should be used regularly even if both or either of the sex partners is HIV positive. Van Dyk et al. (2017) caution that HIV-infected people may re-infect themselves with other strains of the virus if they neglect using condoms. Another risk involves contracting STIs, which further weakens the compromised immune system of a person living with HIV. Condoms, therefore, remain a critical part of HIV-prevention (Simbayi et al., 2006; Velloza et al., 2015).

The fight against HIV-infection forces institutions to find innovative ways to combat the virus. Studies about the promotion of male circumcision as a preventative measure have been conducted in South Africa and other countries such as Kenya and Uganda. Lancet (2007) expounds that in Uganda and Kenya, male circumcision halved the risk of males contracting HIV through heterosexual intercourse. According to the study by Lancet (2007) in Johannesburg, HIV risk is reduced by $60 \%$ as a result of male circumcision. It is worth noting that the male youths who participated in the study were between the ages of 18 and 24 years. Pelzer, Simbayi, Banyini and Kekana (2011) warn that although circumcision reduces the risk of HIV-infection, the process may be undermined by individuals who neglect to use condoms or who increase the number of their sexual partners. It is essential that old preventative measures be adhered to while newer approaches are introduced in the battle against HIV. Pelzer et al. (2011) point out that there is a difference between a clinical circumcision procedure, which is provided with counselling before and after surgery, and a traditional approach. Traditional methods are not necessarily accompanied by pre- and post-counselling, which is imperative for HIV-prevention. Condom use remains critical as an HIV-prevention strategy given that circumcision does not provide 100\% protection against HIV-infection (Lancet, 2007; Machimana \& Nhlanhla, 2020). The correct, consistent use of condoms and male circumcision will reduce the risk of contracting HIV by high percentages, as suggested above.

The use of pre-exposure prophylaxis (PrEP) as a prevention strategy for HIV infection was endorsed by the South African Medicines Control Council in 2015. This was three years after PrEP had been endorsed in the United States (Eaton, Driffin, Bauermeister, Smith \& ConwayWashington, 2015) which indicates that South Africa is not far behind it its prevention interventions when compared to more developed countries. The addition of PrEP as a new prevention tool marked a new era in HIV prevention in high-risk populations such as youths (Maljaars et al., 2017). PrEP involves the administration of ARV's in HIV negative individuals as a form of prevention (Eaton et al., 2015; Maljaars et al., 2017). The correct and consistent use of 
PrEP has been found to be greater than 90\% effective in preventing HIV infection (Velloza et al., 2020). The use of PrEP has been found to be effective among youths with youths on PrEP reporting greater condom usage during PrEP than before they started using PrEP. Maljaars et al. (2017) further argue that the effectiveness of PrEP as a prevention intervention tool lies in its administration as part of a broader prevention package which includes condom usage and STI screening.

\section{Research methodology}

In the current study, we utilized the qualitative research methodology. Qualitative research is the multifaceted collection of perspectives and methods that have developed from different theories and disciplines (Lankshear \& Knobel, 2004). Lankshear and Knobel (2004) indicate that the ontology of qualitative study originates from interpretive sociology. The primary goal of qualitative research is to describe and understand a phenomenon in real life (Babbie, 2013). We were interested in understanding the risk of HIV-infections in male youths associated with alcohol misuse within their natural setting. Qualitative research emphasizes studying human actions within their natural environment (Creswell, 2007).

Data were collected using the interview guide. Neuman (2014) states that qualitative research method collects data in the form of words, i.e., face-to-face interview. The interview guide was used in this research because the study is exploratory in its nature. Dyer (2006) asserts that an interview differs from an ordinary conversation because the interviewer works within ethical guides that help to protect the research participant from exploitation or psychological harm because of taking part in the research. Howitt and Cramer (2008) support this argument by stating that interviews are a highly specialized form of conversation that takes place in a specific context different from normal conversation. In this case, it was an academic context and the interviews required skills, planning and appreciation of the issues involved to conduct successful research. The researchers were confident of their ability to conduct the study given the academic training undertaken; the experience acquired over the years and the planning that has gone into this study.

\section{Results}

4.1 The male youths who are at risk of contracting HIV due to alcohol misuse receive support

The results of the current results are presented under two broad themes, namely; (1) male youths who are at risk of contracting HIV due to alcohol misuse receive support, and (2) what needs to be done to improve the services for male youths who are at risk of contracting HIV. The first theme was derived from the following research questions which were asked during the faceto-face interviews: How do male youths cope with the challenges of the risk of contracting HIV? How does the HWO support male youths? Some of the responses to these questions were quoted in the following sub-headings.

\subsubsection{Individual HIV-prevention strategy}

The male youths who are of the opinion that HIV can be prevented suggested several steps that an individual should take. The male youths understand that they need support in preventing HIV. Still, they felt that individuals must take to responsibility, either by abstaining from sex, using condoms or being faithful to one partner. Participant 1's response highlights how important it is for male youths to take the initiative in HIV-prevention, "Using condoms, or abstaining and being faithful to one partner and waiting for the right time to have sex, which is 
after marriage". Participant 2 was more open and personal about the matter when he said, "I am protecting myself [against HIV] by having one [sexual] partner".

Participant 8 stated that it is vital for male youths to be proactive in preventing HIV. He raised the issue of both sex partners testing for HIV before they have sex. Other research participants concur with the opinions raised about individuals playing a vital role in complementing the institution's HIV intervention strategy:

"If you want to protect yourself, before you sleep with a girl, you should maybe go to a clinic and have an HIV test. After that you get all the information you can have sex" (Participant 1).

"Male youths can be protected [against HIV] by attending workshops so that they can learn from other people. And they can use condoms, others they can prevent or abstain from having sex" (Participant 3).

"Youths can protect themselves by using condoms, going to hospital to get information from the doctors. And ask a person, if you do not understand, ask anyone your mother or your father, if you trust him, he can tell you about HIV" (Participant 4).

\subsubsection{Organizational intervention in HIV-prevention}

The HWO offers support to male youths in various ways. The main focus of the institution is to promote HIV education among the youths who attend their workshops. The contribution, against the spread of HIV, made by the institution, is acknowledged by many of the research participants. The researchers have quoted some of the answers given by the male youths:

"Ok, it [HWO] supports the male youths by advising them how to be responsible for themselves. And by teaching them how to be the good fathers in future. How to handle their families and to know that this world is full of things that you cannot overcome alone. You need some people to help you" (Participant 3).

The value of academic education is highlighted below:

"They advise youths that do not have sex, go to school, you are still a kid. Read and have your goals, do not like girls. Do not try to impress girls with money, you are still a kid and you are under the care of your mom and your father" (Participant 5).

The HWO involves male youths in physical activities:

"It [HWO] helps many young men because they take them off the street. They put them here together and give them activities. There are many activities here and I think that they have a good way of reducing the risk of getting HIV and AIDS. When we are here, we do not think of doing sex. We think of playing soccer, singing; there is where they will talk to us, guide us, and give us a way of life. It helps a lot" (Participant 9).

"The HWO shows them that certain things are good, but other things are not good. That is how we get to know about the dangers and avoid them" (Participant 12). Participant 13 indicated that the male youths who are living with HIV receive both training and medical support: "They train them [male youths] and they always take them for treatment for HIV" (Participant 13).

"They [HWO] support them with many things. Many things like giving them Tshirts of stop HIV and AIDS. Doing posters to make them aware of HIV and AIDS and alcohol can make them be affected with HIV and AIDS" (Participant 14). 
E. G. Machimana et al. - HIV-Infections in Male Youths: Risks Associated with Alcohol Misuse

4.2 What needs to be done to improve the services for male youths who are at risk of contracting $H I V$

\subsubsection{Educational strategies}

In addressing the second theme, the male youths were asked the following question: What could be done to improve the support for male youths who misuse alcohol at the risk of HIVinfection? The research participants affirmed that something positive could be done to assist male youths in preventing the risk of contracting HIV. The male youths believe that educational programs could be improved at the HWO by introducing various strategies. It was suggested that the Trainers at the HWO should offer HIV education at schools. Some of the male youths feel that they need Life Coaches who are dedicated to offering them support. The following are direct quotations from the face-to-face interviews:

"Finding coaches who will give the male youths guidance, so that they can find understanding and know a lot about HIV and AIDS. And help them not to be arrogant, be calm when they talk to them, to follow regulations and rules" (Participant 1).

"Like doing some workshops at schools to guide young people about this HIV and AIDS and the alcohol. How HIV and AIDS affects and how it destroys a young person, while she or he is young" (Participant 3).

Some of the research participants support the idea of HIV and AIDS education, but they emphasize the need to highlight the link between alcohol misuse and the risk of contracting HIV. The male youths who spoke about the link between alcohol misuse and the risk of contracting HIV felt strongly about targeting taverns with HIV-prevention education. The male youths proposed that all taverns and shopping centers should be more explicit in communicating HIVprevention messages. Participant 10 made the following comment during the face-to-face interview:

"The HWO do teach us about sex and that we should abstain. They should also teach us about alcohol and how it affects the body. This will help us to stay away from alcohol" (Participant 10).

Participant 5 is one of the research participants who specifically spoke about reaching out to taverns and shopping centers, with HIV campaigns. The quotation below reflects his feeling and that of others about the importance of intensifying HIV communication strategies:

"Get posters to shebeens and shopping centers. Go to the mall and advise youths not to go to shebeens when they are underage, but they must go when they are grown up. Go [Youths must go] to school and do not go to shebeens"(Participant 5).

"Maybe send the posters to each household, that will show that stop unprotected sex. Avoid having more drinks. Drink water more than beer" (Participant 14).

Participant 4 is one of the few individuals who felt that male youths are receiving a good and appropriate education concerning HIV and AIDS. He feels that the hindrance in HIVprevention is the fact that male youths resist taking responsibility after being taught. In his own words, this is what he had to say:

"At times male youths do not listen, but they give them the condoms. They tell them how to be free with AIDS and go to school too. They teach them about HIV and AIDS" (Participant 4).

Most research participants highlighted the importance of using condoms as a preventative measure against the spread of HIV. The male youths quoted below feel that people living with HIV should stop drinking alcohol as it is not good for their health. Another challenge is that when alcohol is misused, it may lead them to indulge in risky sexual intercourse: 
"About the HIV is that; there are condoms outside there. If you feel that you are ready to have sex, go to the clinic, tell the nurses and the doctors to give you the condom or abstain from having sex. Abstain up until you get married or you are ready to have sex" (Participant 3).

"To show all people who are here, the people who are infected with HIV they must stop drinking and having sex. They must stop "mujolo" [sexual relationships] because some of them they go to the passages and kiss each other. It is not good" (Participant 7).

\subsubsection{Activities-linked HIV-prevention strategies}

Several research participants suggested that HIV-prevention strategies should be linked to certain activities that male youths will enjoy. They acknowledged that the HWO is already implementing some of the activities. The research participants feel that the proposed activities will attract male youths to the organization and get them interested in HIV and AIDS education messages. Beyond the attendance of the activities, the participants believe that male youths will change their sexual behavior for the better. The following are direct quotations from some of the research participants who responded to the question of, what could be done to improve HIVprevention in male youths:

"I think the HWO has done a lot because there are the activities. Like during the school holidays, we come here every day. We do lots of activities, like there are others doing soccer. Like they take us and group us. After grouping us they teach us about HIV and AIDS and say you must not do one two" (Participant 8).

"I think they should give the male youths more activities than they are giving, because now is just singing and soccer only. Most of the people they do not love singing or playing soccer, but there are these games that they like. I think maybe if they could introduce more games, more youths will come" (Participant 1).

"Ok like, I could say dancing. Most of the youths here in Soshanguve, they like dancing. Dancing can take many young men off the street. Dancing, dramas, poetry and many things" (Participant 9).

"When you want something, they must pay attention to you. They should teach us drama. When they see that you are able, they must call a professional, perhaps one day you will be on TV" (Participant 11).

The themes that were developed in this research are based on the face-to-face interviews with the male youths. The transcripts indicate that male youths have the understanding that the misuse of alcohol may pose the risk of contracting HIV.

\section{Discussion}

5.1 The male youths who are at risk of contracting HIV due to alcohol misuse receive support

All the research participants acknowledged that they received support, on dealing with HIV risk, from the HWO. Participant 8 commented on the HWO, "It supports male youths because it helps us to stay away from trouble". In this context, staying away from trouble includes abstaining from alcohol and risky sexual behavior. The notion expressed above is confirmed by participant 14 when he said, "They [The HWO] support them with many things. Many things like giving them T-shirts of stop HIV and AIDS". The support offered to the male youths extends to their social needs as they are given food at the center, which is much needed by youths from poorer 
families. Part of the food is donated by local businesses, and this broadens the support that the male youths receive.

The following comment further highlighted that male youths receive information and medical support from the organization, "They train them [male youths] and they always take them for treatment for HIV" (Participant 13). The male youths appreciate this kind of support as it is a positive contribution to preventing HIV, and this will go a long way towards remedying the impact of the virus. The understanding of the male youths about the value of support agrees with the literature reviewed (Machimana \& Nhlanhla, 2020; Velloza et al., 2020). There is a need for knowledge and information that helps youths build resilience to tackle life challenges (LoveLife, 2020; Machimana et al., 2020). The research participants recognize that if no structured support were offered by the organization, many of them would be engaged in activities that might expose them to HIV. The following quotation highlights the point:

"It helps many young men because they take them off the street. They put them here together and give them activities. There are many activities here, and I think that they have a good way of reducing the risk of getting HIV and AIDS. When we are here, we do not think of doing sex. We think of playing soccer, singing, there is where they will talk to us, guide us, and give us a way of life. It helps a lot" (Participant 9).

Van Dyk et al. (2017) argue that it is of paramount importance to build a strong support system that will allow youths to share their experiences in a friendly environment. The support system should be designed within the cultural context of adolescents (Poindexter, 2010). For example, in some cultures individuality is more valued than communal structures. The research participants seemed to like communal support as they emphasized the value of group workshops and team sports. The communal support structure could be derived from the concept of "ubuntu", simply translated as "togetherness", which is common among African cultures (Wojcicki, 2002; Dalamo, 2013). Participant 5's comment shows that male youths have an understanding that the support should be viewed in the broader context, that involves family relations:

"They advise youths that do not have sex, go to school, you are still a kid. Read and have your goals, do not like girls. Do not try to impress girls with money, you are still a kid and you are under the care your mom and your father" (Participant 5).

The first theme discussed the importance of involving the significant other parties, for example parents, in HIV-prevention programs for male youths. Other research recommends the involvement of parents and families in adolescents' HIV-prevention programs (Perrino et al., 2000). It is creditable to see an agreement between literature and field data about providing support for male youth.

5.2 What needs to be done to improve the services for male youths who are at risk of contracting $H I V$

Male youths value the support offered by the HWO; however, they felt more could be done to improve the service. The male youths recommend that there should be more workshops, that they should be linked to Life Coaches, who will mentor and guide them in life choices. Participant 12's sentiment was shared by other research participants, "If we could have more group discussions to guide each other, like LoveLife". The main anxieties concerning life choices were about alcohol misuse and risky sexual behaviors in male youths.

In addition, they suggested that the Trainers at the HWO should visit their schools more often to strengthen the support. The findings of this study point out the outcry of male youths for the need for role models. LoveLife (2020) notes that youths feel there is a lack of role models 
at the community level and in the media. The HWO may have a greater impact on the community if they use peers as role models to model positive sexual behavior. LoveLife (2020) is among the pioneering organizations that are modelling peer education in HIV-prevention, for example, the "mpintshi" flagship. In line with Bandura's Social Learning Theory, role modelling serves to strengthen a particular behavior (Schultz \& Schultz 2017). In this case, role modelling could be used to encourage male youths not to misuse alcohol and avoid risky sexual behavior.

The research participants mentioned that they are taught about alcohol misuse and its association with the spread of HIV, as reflected in the findings. It emerged in this study that male youths would like to receive more information and education about the effects of alcohol and its relationship with HIV. The male youths have witnessed some of the devastating effects of alcohol misuse in their community; hence they suggest:

"The HWO do teach us about sex and that we should abstain. They should also teach us about alcohol and how it affects the body. This will help us to stay away from alcohol" (Participant 10).

HIV-prevention programs that are targeted for youths should adequately tackle alcohol misuse and the risky sexual behavior associated with it (National Institute on Alcohol Abuse and Alcoholism, 2002). The link of alcohol information to HIV-prevention programs will strengthen the existing interventions. Participant 5 substantiated this stand when he said:

"Get posters to shebeens and shopping centers. Go to the mall and advise youths not to go to shebeens when they are underage, but they must go when they are grown up. Go [Youths must go] to school and do not go to shebeens"(Participant 5).

Other studies affirm that discouraging underage drinking may eliminate problems related to alcohol misuse, including HIV-infections (Parry, 2005, Velloza et al., 2015; Machimana \& Nhlanhla, 2020). It is critical also to target the taverns with HIV-prevention strategies because some risky sexual behavior emanates from or occurs in such places (Velloza et al., 2015). HIVprevention interventions that are designed specifically for young men who misuse alcohol will improve the services for this target group (Kalichman, Simbayi, Kaufman, Cain \& Jooste, 2007; Parry et al., 2010).

All the youths who participated in the study indicated that they are actively involved in the activities of the organizations. They mainly participate in soccer and singing. Participant 11 and participant 9 suggested that the organization should include drama and dancing as part of the youths' activities. The following quotations illustrate their feelings about these activities:

"They should teach us drama. When they see that you are able, they must call a professional, perhaps one day you will be on TV' (Participant 11). Ok, like, I could say dancing. Most of the youths here in Soshanguve, they like dancing. Dancing can take many young men off the street. Dancing, dramas and many things" (Participant 9).

Drama was one of those activities about which the research participants had conflicting views. The confusing message about drama is that some research participants indicated that the organization was already providing it, whilst some of them suggested it as a new activity. All research participants have a common view about its value, and they recommend it as part of the youth activities. From literature, these activities are seen as very important, and in addition, suggest that sport coaches should have appropriate information and education about HIVtransmission (Van Dyk et al., 2017). The sports coaches could use some of the time they spend on the sport field to educate the young men about HIV. They should also use the information to prevent the spread of HIV through blood transfusions, especially when there is an injury on the field. It is evident in this paper that male youths are aware of and concerned about contracting HIV through contaminated blood. 
Moreover, Karim and Karim (2010) assert that risky sexual behavior is linked to how young people use their leisure time. Community organizations that provide structured activities for young men are assisting with getting them to use their leisure time constructively, thus avoiding engaging in risky sexual behavior. LoveLife (2008: 7) states that good TV programs like "Imagine Afrika" are inspirational to youths and they can dispel HIV myths. It is therefore recommended that the HWO should consider the suggestions proposed by the male youths. Chances are the male youths will buy into or take ownership of these activities, as they themselves recommended them.

\section{Conclusion}

The male youths know about the association of alcohol misuse and the risk of contracting HIV, yet many of them remain vulnerable to the disease. Their knowledge of risky sexual behaviors does not always translate into HIV-preventative actions, especially when under the influence of alcohol. The male youths appreciate the HIV support program provided by the HWO. The research participants recommended several ideas that could be introduced to improve the policies, programs and services of the HWO. The research participants believe that the improved policies will contribute to the prevention of HIV infection associated with alcohol misuse.

The findings of the study are consistent with the relevant literature in HIV/AIDS. Many of the male youths are aware of HIV-preventative methods, but their behavior is not always in line with such practices, for example, condom use during sexual intercourse. It is apparent that the battle against HIV continues and newer preventative strategies, such as male circumcision and the use of PrEP may improve the prevention strategy if accompanied by existing methods. We recommend that male youth should be taught about the risk of HIV infection associated with alcohol misuse in various places such as institutions, schools, taverns, and sports fields. HIV and AIDS policies and programs should emphasize the practical intervention strategies for HIVprevention. For example, condom use should not be neglected in favor of newer HIV-preventative strategies such as male circumcision and PrEP. Both condom use and male circumcision should be viewed as complementary methods.

\section{Acknowledgements}

The researchers would like to thank the management of the Health and Welfare Organisation for granting us permission to interview the male youths at the center. We would like to express our very great appreciation to the research participants for generously sharing their time, experience and knowledge about HIV and AIDS.

This research did not receive any specific grant from funding agencies in the public commercial, or not-for-profit sectors.

The authors declare no competing interests. 


\section{References}

Albertyn, C. (2003). Contesting democracy: HIV/AIDS and the achievement of gender equality in South Africa. Feminist Studies, 29(3), 594-615.

Alcorn, K. (2011). Treatment is prevention! HATiP HIV \& AIDS Treatment in Practice, 180, 1-19.

Babbie, E. (2013). The practice of social research (13 $3^{\text {th }}$ ed.). Belmont, CA: Wadsworth Cengage Learning.

Creswell, J. W. (2007). Educational research: Planning, conducting and evaluating quantitative and qualitative research. New York: Pearson Prentice Hall.

Dyer, C. (2006). Research in psychology: A practical guide to methods and statistics. Oxford: Blackwell Publishing.

Dalamo, R. (2013). Botho/Ubunto: The heart of African ethics. Scriptura, 112(1), 1-10.

Eaton, L. A., Driffin, D. D., Bauermeister, J., Smith, H., \& Conway-Washington, C. (2015). Minimal awareness and stalled uptake of pre-exposure prophylaxis (PrEP) among at risk, HIV-negative, Black men who have sex with men. AIDS Patient Care and STDs, 29(8), 423-430. https://doi.org/10.1089/apc.2014.0303

Evian, C. (2003). Primary HIV/AIDS Care: A practical guide for primary health care personnel in the clinical supportive care of people with HIV/AIDS ( $4^{\text {th }}$ ed.). Durban: Jacana Media.

Fassin, D., \& Schneider, H. (2003). The politics of AIDS in South Africa: Beyond the controversies. Education and Debate, 326, 495-497.

Howitt, D., \& Cramer, D. (2008). Introduction to research methods in psychology (2 ${ }^{\text {nd }}$ ed.). London: Pearson Education.

Kalichman, S. C., Simbayi, L. C., Kaufman, M., Cain, D., \& Jooste, S. (2007). Alcohol use and sexual risks for HIV/AIDS in Sub-Saharan Africa: Systematic review of empirical findings. Society of Prevention Research, 8, 141-149.

Kalichman, S. C., Simbayi, L. C., Vermaak, R., Jooste, S., \& Cain, D. (2008). HIV/AIDS risks among men and women who drink at informal alcohol serving establishments (shebeens) in Cape Town, South Africa. Society for Prevention Research, 55-62.

Karim, Q. A., \& Karim, S. S. A. (Eds.). (2010). HIV/AIDS in South Africa (2 ${ }^{\text {nd }}$ ed.). Cape Town: Cambridge University Press.

Khosa, N., Stadler, J., MacPhail, C., Chikandiwa, A., Brahmbhatt, H., \& Delany-Moretlwe, S. (2018). Cash transfer interventions for sexual health: Meanings and experiences of adolescent males and females in inner-city Johannesburg. Bio Medical Central Public Health, 18(120), 1-11. https://doi.org/10.1186/s12889-018-5027-3

Lancet (2007). Male circumcision to cut HIV risk in the general population. The Lancet, 369, 615-619.

Lankshear, C., \& Knobel, M. (2004). A handbook for teacher research from design to implementation. England: MvGraw-Hill.

Ledwaba, L. (2010). South Africa faces R4obn yearly HIV/AIDS bill-report. City Press. 28 November: 12.

LoveLife (2008). HIV prevention for young people: Moving from what-to change to want-to-change strategies, 1-23. Retrieved from https://lovelife.org.za/en/CONFERENCE_FINAL.pdf.

LoveLife (2020). Boy child programme. Retrieved from https://lovelife.org.za/en/programmes/.

Machimana, E. G. (2012). Perceptions of the association between alcohol misuse and the risk of HIVinfection among male youths in Soshanguve, Gauteng province, University of South Africa, Pretoria. (Master's dissertation). Retrieved from 
E. G. Machimana et al. - HIV-Infections in Male Youths: Risks Associated with Alcohol Misuse

http://uir.unisa.ac.za/bitstream/handle/10500/9129/Dissertation machimana eg.pdf?sequ ence $=1 /$.

Machimana, E. G., \& Nhlanhla, P. (2020). Male youths' perceptions, knowledge and beliefs of alcohol misuse and HIV prevention. Open Journal for Sociological Studies, 4(1), 1-12. https://doi.org/10.32591/coas.ojss.0401.01001m

Machimana, E. G., Sefotho, M, M., Ebersöhn, L., \& Shultz, L. (2020). Higher education uses community engagement-partnership as a research space to build knowledge. Educational Research for Policy and Practice. Retrieved from http://link.springer.com/article/10.1007/s10671-020$\underline{\text { 09266-6 }}$

Majozi, P. N. N. (2009). Investigating anxiety and social support in adults diagnosed with HIV or AIDS in a public health facility in the Western Cape Province. University of the Western Cape, Cape Town (Master's dissertation). Retrieved from http://etd.uwc.ac.za/xmlui/bitstream/handle/11394/3465/majozi mpsych 2010.pdf?seque nce $=1 /$.

Maljaars, L. P., Gill, K., Smith, P. J., Gray, G. E., Dietrich, J. J., Gomez, G. B., \& Bekker, L. (2017). Condom migration after introduction of pre-exposure prophylaxis among HIV-uninfected adolescents in South Africa: A cohort analysis. Southern African Journal of HIV Medicine, 18(1). a712. https://doi.org/10.4102/sajhivmed.v18i1.712

Maxwell, J. A. (2013). Qualitative research design: An interactive approach (3 ${ }^{\text {rd }}$ ed.). Los Angeles: SAGE.

National Institute on Alcohol Abuse and Alcoholism (2002). Alcohol alert. National Institute on Alcohol Abuse and Alcoholism, 1-5.

Ndinga-Mavumba, A., \& Pharoah R. (Eds.). (2008). HIV/AIDS and Society in South Africa. Pietermaritzburg: University of KwaZulu-Natal Press.

Neuman, W. L. (2014). Basics of social research: Qualitative and quantitative approaches (3 ${ }^{\text {rd }}$ ed.). Edinburgh: Pearson.

Parry, C. D. H., Myers, B., \& Michael, T. (2003). The case for an increased tax on alcohol in South Africa. SAJE, 71(2), 137-145.

Parry, C. D. H. (2005). A review of policy-relevant strategies and interventions to address the burden of alcohol on individuals and society in South Africa. South African Psychiatry Review, 8, 20-24.

Parry, C. D. H., Rehm, J., \& Morojele, N. K. (2010). Is there a causal relationship between alcohol and HIV? Implications for policy, practice and future research. African Journal of Drug \& Alcohol Studies, 9(2), 81-91.

Pelzer, K., Simbayi, H. L., Banyini, M., \& Kekana, Q. (2011). HIV risk reduction intervention among traditionally circumcised young men in South Africa: A cluster randomised control trial. Journal of the association of nurses in the AIDS care, 1-10.

Perrino, T., Gonzalez-Soldevilla, A., Pantin, H., \& Szapocznik, J. (2000). The role of families in adolescent HIV prevention: A review. Clinical Child and Family Psychology Review, 3(2), 81-96.

Piot, P. (2003). Accelerating action against AIDS in Africa. Geneva: UNAIDS.

Quinn, N. (2010). The cultural analysis of discourse. In W. Luttrell (Ed.), Qualitative educational research: Readings in reflexive methodology and transformative practice (pp. 237-257). New York, NY: Routledge.

Rees, V., Saitz, R., Horton, N. J., \& Samet, J. (2001). Association of alcohol consumption with HIV sex-and drug-risk behaviours among drug users. Journal of Substance Abuse Treatment, 21, 129-134.

Santrock, J. W. (2018). Educational psychology (6 ${ }^{\text {th }}$ ed.). New York: McGraw-Hill.

Schultz, D. P., \& Schultz, S. E. (2017). The theories of personality (11 ${ }^{\text {th }}$ ed.). Boston, MA: Cengage Learning. 
Simbayi, L. C., Mwaba, K., \& Kalichman, S. C. (2006). Perceptions of the combination of HIV/AIDS and alcohol as a risk among STI clinic attenders in South Africa: Implications for HIV prevention. Social Behaviour and Personality, 34(5), 535-544.

Shisana, O., Rehle, T., Simbayi, L. C., Zuma, K., Jooste, S., Zungu, N., ... Onoya, D. (2014). South African national HIV prevalence, incidence, behaviour survey 2012. Cape Town: HSRC Press.

Van Dyk, A., Tlou, E., \& Van Dyk, P. (2017). HIV/AIDS care \& counselling: A multidisciplinary approach ( $6^{\text {th }}$ ed.). Cape Town: Pearson Education South Africa.

Velloza, J. Watt, M. H., Choi, W., Abler, L., Kalichman, S. C., Skinner, D., ... Sikkema, K. J. (2015). HIV/AIDS-related stigma in South African alcohol-serving venues and its potential impact on HIV disclosure, testing, and treatment-seeking behaviours. Glob Public Health, 1O(9), 10921106. https://doi.org/10.1080/17441692.2014.1001767

Velloza, J., Khoza, N., Scorgie, F., Chitukuta, M., Mutero, P., Mutiti, K., ... Delany-Moretlwe, S. (2020). The influence of HIV-related stigma on PrEP disclosure and adherence among adolescent girls and young women in HPTN 082: A qualitative study. Journal of International AIDS Society, 23e25463. https://doi.org/10.1002/jia2.25463

Wojcicki, J. M. (2002). "She drank his money": Survival sex and the problem of violence in taverns in Gauteng Province, South Africa. Medical Anthropology Quarterly, 16(13), 267-293.

Woods, S. (Ed.) (2004). Focus HIV and young people: The threat for today's youth. Report on the global HIV and AIDS epidemic, $4^{\text {th }}, 95$. 
E. G. Machimana et al. - HIV-Infections in Male Youths: Risks Associated with Alcohol Misuse 